\title{
Obituary
}

\section{Lev Andreevich Artsimovich}

LeV ANDREeVICH ARTSIMOVICH, the Soviet physicist, died on March 1, 1973.

Artsimovich, the son of a professor of statistics, was born on February 25, 1909, in Moscow. At nineteen years of age he graduated from the Byelorussian State University, in Minsk, and then began work at the Leningrad Physico-Technical Institute, where he was a student of A. F. Ioffe. From 1930 onwards, he taught at a number of higher educational and research institutes in Moscow and Leningrad, including Leningrad State University and the Leningrad Polytechnic Institute. From 1930 to 1948 he worked at the Physico-Technical Institute of the Academy of Sciences of the USSR, and between 1959 and 1963 he was Academic Secretary of the Department of Physico-Mathematical Sciences of the Academy. $\mathrm{He}$ was elected a corresponding member of the Academy in 1946 and a full member in 1953. In 1963 he became senior associate and Deputy Head of the Institute of Atomic Energy of the Academy, and was made a member of the Editorial Board of the Doklady of the Academy in 1960.

Artsimovich began his research with the study of X-ray optics and the problem of total X-ray reflexion. Between 1934 and 1935 he studied properties of $\left(n_{1} n\right)$ and $\left(n_{1} p\right)$ interactions. Work which he carried out in collaboration with I. V. Kurchatov and others was among the first demonstration of the large magnitude of slow neutron capture cross section. In 1936, together with A. I. Alikhanov and A. I. Alikhanyan, he carried out an experiment which clearly confirmed the laws of conservation in electronpositron annihilation and refuted Shenkland's postulate that in this case the basic laws were violated.

During the end of the $1930 \mathrm{~s}$, Artsimovich was chiefly concerned with the interaction of fast electrons with matter. Then experimental data on bremsstrahlung and the angular distribution of scattered electrons differed from the accepted theory by two orders of magnitude. In an extensive series of experiments, Artsimovich succeeded in showing that the quantum-mechanical theory of the passage of fast electrons through matter agreed with experimental data to within the limits of experimental error.

During the war, Artsimovich worked on the theory of chromatic aberrations in electron-optical systems, carrying out considerable theoretical and experimental research on electron-optical converters. In 1945, together with L. Ya. Pomeranchuk, he carried out theoretical research on radiation losses in betatrons, which enabled the maximum energy achievable by betatron acceleration to be increased. $\mathrm{He}$ also formed part of a team which developed an electromagnetic method of isotope separation, being himself responsible for designing the optics of the ion source.
At the beginning of the 1950s, Artismovich began studying the possibilities of controlled thermonuclear reactions, investigating high current pulse discharges in low pressure deuterium. During these experiments Artsimovich and his team succeeded in obtaining a highly ionized plasma of $1,000,000^{\circ}$ C. In 1952 they discovered that a powerful pulse discharge in low pressure deuterium is a source of neutrons and short-wave $\mathbf{X}$ rays. Later, they demonstrated that the gas discharge plasma, compressed in the presence of a longitudinal magnetic field, possesses paramagnetic properties. They also showed that the neutrons originate not from thermonuclear reactions but from a specific acceleration process. Artsimovich was then increasingly associated with Soviet progress in thermonuclear research, and in 1958 he presented a report on Soviet research in this field to the Second World Congress on the Peaceful Uses of Atomic Energy. During the 1960s he played a leading part in research on Tokamaks, and achieved a longduration stable plasma with a density of up to $10^{14}$ ions $\mathrm{cm}^{-3}$ and temperature of up to $5,000,000^{\circ}$ C. For his work in this field, he was awarded a number of Soviet honours, including the Order of Lenin (four times), the order of the Red Banner of Labour (twice) and the Lenin Prize (1958). In 1965 he was awarded the Czechoslovak medal, and in $\mathbf{1 9 6 6}$ was elected a foreign member of the Czechoslovak Academy of Sciences.

\section{HOW TO BUY NATURE}

The cost of one year's subscription to NATURE is:

UK \& elsewhere US \& Canada

Nature (Friday)

£16

£20

Nature \& Nature Physical Science

or Nature New Biology

£24

f33

Nature New Biology or Nature

Physical Science

£10

f15

All three editions

$£ 29.50$

$€ 44$

Index (1972)

f1

$\$ 1.50$

(Charges for delivery by air mail on application). Subscribers in North America may be able to claim a tax rebate against their NATURE subscription.
Editorial, Advertising and Publishing Offices of NATURE

MACMILLAN JOURNALS LIMITED

4 LITTLE ESSEX STREET, LONDON WC2R 3LF

Telephone Number: 01-836 6633. Telegrams: Phusis London WC2R 3LF Telex 262024

MACMILLAN JOURNALS LIMITED

711 NATIONAL PRESS BUILDING

WASHINGTON DC 20004

Telephone Number: 202-737 2355. Telex 64280

Advertisement Department

MACMILLAN JOURNALS LIMITED

4 LITTLE ESSEX STREET, LONDON WC2R 3LF

Telephone Numbers : UK 01-836 6633. USA 202-737 2355

Subscription Department

MACMILLAN JOURNALS LIMITED

BRUNEL ROAD, BASINGSTOKE, HANTS RG21 2XS

Telephone Number: Basingstoke 29242

Classified advertisements

T. G. SCOTT \& SON, LIMITED

1 CLEMENT'S INN, LONDON WC2A 2ED

Telephone Number : 01-242 6264/01-405 4743

Telegrams : Textualist London WC2A 2ED

Registered as a newspaper at the Post Office

Copyright (C) Macmillan Journals Limited, July 271973 